\title{
Healthy Minds: Group Cognitive-Behavioral Intervention for Sustainable Return to Work After a Sick Leave Due to Depression
}

\author{
Marc Corbière ${ }^{1,2}$ (1) $\cdot$ Jean-Philippe Lachance ${ }^{2,3} \cdot$ Francelyne Jean-Baptiste $^{2} \cdot$ Catherine Hache-Labelle $^{2,4}$. \\ Gabrielle Riopel $^{2,4} \cdot$ Tania Lecomte ${ }^{2,4}$
}

Accepted: 21 June 2021 / Published online: 19 July 2021

(c) The Author(s), under exclusive licence to Springer Science+Business Media, LLC, part of Springer Nature 2021

\begin{abstract}
Background Depression is one of the major causes for sick leave and loss of productivity at work. Many studies have investigated return to work (RTW) interventions for people with common mental disorders. However, a paucity of studies has targeted depressive symptoms in the workplace, as well as work productivity. Objectives This study presents preliminary results on a novel group intervention based on cognitive behavioral principles in order to optimize sustainable RTW, by reducing clinical symptoms (anxiety and depression) and improving work productivity. Method This pilot study followed a quasi-experimental design, with participants randomly receiving the group intervention $(N=19)$ or only receiving usual services ( $\mathrm{N}=11$, control group). The group intervention called Healthy Minds for Sustainable RTW consists of eight sessions based on cognitive behavioral therapy principles and techniques. Outcome measures on depressive and anxiety symptoms and work productivity were administered at baseline (i.e. the start of return-to-work or gradual RTW), as well 2 months later (post-intervention), and at 6-month follow-up. Results The results did not show a time $\times$ group interaction for symptoms of depression or anxiety $(\mathrm{p}=0.07)$. Those who received the group intervention however did see a within-group reduction in anxiety and depressive symptoms over time, clinically significant for the group intervention only. A significant time $x$ group interaction for work productivity was found, with those in the intervention group improving over time compared to the control condition. Conclusion Although replication is needed, these results suggest that a brief group cognitive-behavioral intervention specifically tailored to work-related issues is promising. Future studies are warranted, particularly with larger samples and remote webconferencing delivery.
\end{abstract}

Keywords Return-to-work · Workplace · Depression · Group intervention · Cognitive behavioral therapy

\section{Introduction}

Depression is one of the most common mental disorders [1]. In Canada and around the world, the annual prevalence rate of depression ranges from 4 to $6 \%$, whereas the lifetime

Marc Corbière

corbiere.marc@uqam.ca

1 Faculty of Educational Sciences, Université of Québec à Montréal, 1205, Rue Saint-Denis, Montréal, QC H2X 3R9, Canada

2 Research Center of the Institut universitaire en santé mentale de Montréal, Montreal, Canada

3 Health and Society Institute, Université du Québec à Montréal, Montreal, Canada

4 Department of Psychology, Université de Montréal, Montreal, Canada prevalence rate is twice as high (from 10 to $12 \%$ [2-5]. In 2005, the World Health Organization (WHO) predicted that by 2020 , depression would become one of the three leading causes of work disability [6], a prognosis that has been confirmed. By 2030, depression is expected to become the leading cause of illness in the world [7]. Common mental disorders (CMDs), including depression, currently account for 30 to $50 \%$ of all periods of sick leave at work [8]. Although most employees will return to work, this process can often be long, and complicated $[1,9]$. It is also important to keep in mind that many individuals who experienced a depressive episode will continue to struggle with depressive symptoms over time, with as many as $60 \%$ being at risk of experiencing another depression in the next 2 years $[10,11]$. Depression at work involves symptoms such as fatigue, irritability towards others, and loss of interest in tasks and goals [12]. People with depression also frequently experience anxiety 
symptoms, with prevalence rates ranging from 55 to $75 \%$ [8, 13-17]. Depression can also affect an individual's cognitive functions and result in decreased concentration and attention, loss of alertness, impaired decision-making abilities, impaired organizational abilities (e.g., multi-tasking) and difficulties in meeting deadlines [18]. In addition, depression can bring a significant drop in self-esteem, leading people to feel guilty and think that they are disliked, judged, or no longer useful in the workplace [19]. Such beliefs and perceptions are considered cognitive biases; meaning individuals will erroneously evaluate experiences through a biased lens, diminishing positive events, amplifying negative events, overgeneralizing, catastrophizing or selectively selecting the information that confirms the depressive thoughts [20,21]. Altogether, these biases may result in deeply held beliefs that one is incapable of keeping a job or even too unstable or fragile to work. In the end, we observe significantly reduced work productivity, intermittent absences and sometimes prolonged absence from the labor market [12, 18, 19, 22-26].

Systematic reviews, including meta-analyses, have examined the effectiveness of psychological interventions in reducing sickness absence and RTW due to CMDs or musculoskeletal disorders, compared to control groups [8, 27]. Most of these psychological treatments were based on cognitive-behavioral approaches [8, 27]. In one meta-analysis, CBT was found to reduce the risk of depression relapse by approximately $25 \%$, even up to two years after followup. The effect size was similar to that of medication, but of longer duration [11]. These interventions had only a small positive effect or no effect on RTW for patients on sickness absence due to CMDs and/or musculoskeletal disorders but reduced the number of sick-leave days for those receiving the intervention (about 13 days, with a low effect size). In both meta-analyses, authors noted that most trials did not specifically address the work context, but rather aimed more broadly at symptomatic improvement for CMDs $[8,27]$.

In their Cochrane review on interventions to improve RTW for people with depression, Nieuwenhuijsen et al. [25] showed that adding a work-directed intervention (e.g., work modification, problem solving) to a psychological or pharmacological intervention reduced the number of days on sick leave compared to a clinical intervention alone. On the 23 studies included in their meta-analysis, only five were workdirected interventions. After dividing interventions in four domains (Health-focused interventions, Service coordination interventions, Work modification interventions, Multidomain interventions including 2 or 3 components from previous interventions), Cullen et al. [15]'s meta-analysis showed that Cognitive behavioral therapy (CBT) programs focused on work relevant solutions (e.g., service coordination, work modification or multi-domain interventions) for people with a CMD showed a strong level of evidence for a positive effect on both reducing lost time and costs associated with work disability. Additionally, they observed a moderate level of evidence that work-focused CBT programs had a positive effect on work functioning after RTW due to CMDs. As such, they recommended implementing work-focused CBT interventions and to invite practitioners to target work functioning/productivity improvement after RTW. As described by Nieuwenhuijsen et al. [25], there is a paucity of intervention studies focusing on mental health in the workplace [8], particularly on depression [10].

It is well documented that a reduction in job performance often persists after returning to work, particularly for people who experienced depression [28, 29]. Even though several authors suggest that mental disorders such as depression have a high recurrence rate, symptomatic relapse is not always associated with illness-related absence, with some individuals struggling to perform their work tasks but still showing up at work [22, 23]. Yet, as Arends et al. [24] highlighted in their study, several workers who returned to work after a sick leave due to a CMD such as depression still experienced important depressive and anxiety symptoms and had a lower functioning at work compared to that of the general population, a few months after their return-to work (RTW). Nieuwenhuijsen et al. [25] explained that depressed workers need to make extra efforts (cognitively and physically) to meet work demands, which may lead to more fatigue at the end of the workday. As such, an important concern is the work productivity of people returning to work after a period of sick leave due to depression [26].

Arends et al. [16] conducted a clustered randomized controlled trial (RCT) comparing people with CMDs who were returning to work and who participated in their intervention (called SHARP for Stimulating Healthy participation And Relapse Prevention at work) or not. The SHARP intervention was conceived for preventing recurrent sickness absence and for helping workers maintain their work. Results showed that the 80 workers enrolled in the SHARP group (compared to care as usual) showed a significantly lower incidence of recurrent sickness, although the percentage of individuals on sick leave at 6 and 12 month follow-ups remained high (21\% and $34 \%$ respectively) [16]. In a more recent pilot study, Ito et al. [17] investigated the initial efficacy of a work-focused cognitive behavioral group therapy for workers on sick leave due to depression. Results suggested the possibility that this group CBT with a focus on work, may be a feasible and promising intervention for Japanese workers on leave due to depression. To overcome the limits of this study, authors recommended additional research examining effectiveness of such interventions using control groups such as in a RCT. Furthermore, the use of a group format for delivering CBT to depressed workers could have several advantages, when compared to individual CBT [30-32]. Indeed, a group context, particularly one inspired by a cognitivebehavioral approach, can improve the cost-effectiveness 
of an intervention, offer the possibility of sharing coping strategies, and increase socialization and normalization by realizing others can experience similar difficulties [30,31]. Opting for group therapy also provides an opportunity for participants to increase their social support, thereby reducing aspects of depression such as social isolation [32].

To conclude, return-to-work intervention studies encourage to keep in mind job-specificity, work functioning/productivity, and sustainable RTW when addressing depression or depressive symptoms [18, 33]. However, little is known about how employees with depression function at work [24] and if CBT work-focused interventions offered in a group format could help diminish clinical symptoms (depressive and anxiety) and increase work productivity (upon their return to work) for employees on sick leave due to CMDs like depression [17]. The proposed study consists of determining the impact of a group cognitive-behavioral intervention for sustainable RTW (called Healthy Minds), designed for people with depression who recently returned to work, on symptoms, and work productivity. The hypotheses are as follows:

H1 The Healthy Minds intervention will be effective in diminishing depressive symptoms across time (from preintervention to post-intervention, and from pre-intervention to 6-month follow-up) for those in the experimental group compared to the control group.

H2 The Healthy Minds intervention will be effective in diminishing anxiety symptoms across time (from pre-intervention to post-intervention, and from pre-intervention to 6-month follow-up) for those in the experimental group compared to the control group.

H3 The Healthy Minds intervention will be effective in improving work productivity across time (from pre-intervention to post-intervention, and from pre-intervention to 6-month follow-up) for those in the experimental group compared to the control group.

\section{Methods}

\section{Study Design}

This quasi-experimental study randomly recruited participants by alternatively (each week) approaching participants to either take part in the Healthy Minds group or to take part in a study on depression at work (control condition). Those in the control condition were not informed that they were in a control condition for an intervention study since, from our experience with previous studies with this population, this information can lead to high drop-out rates. Measures were administered at baseline, as well as 2 months later (or post-intervention for those receiving the Healthy Minds group intervention), and at six-month follow-up.

\section{Participants}

A total of 30 subjects stemming from several rehabilitation clinics and clinical programs were recruited. Professionals from over 40 work rehabilitation clinics across Quebec were contacted via email and presented with the outline of the study. These clinics were asked to share the information with their clients who met our inclusion criteria. More information was delivered over the phone to interested potential participants. Inclusion criteria were: (1) returned to work (part-time or full-time) in the past 3 months (as suggested by Arends et al. [16]) or returning within the next month, after a work absence due to depression; (2) reported diagnosis of depression (reason for sick leave as confirmed by the rehabilitation clinic and the Structured Clinical Interview for the DSM-IV (SCID) [34]). Exclusion criteria were: inability to communicate in French or English, having a known organic disorder or intellectual disability, and currently or having previously received CBT for depression in the past 2 years. We did
Table 1 Sociodemographic information

\begin{tabular}{lll}
\hline Variables & $\begin{array}{l}\text { Intervention group } \\
(\mathrm{n}=19) \\
\text { Female }=16(84 \%)\end{array}$ & $\begin{array}{l}\text { Control group }(\mathrm{n}=11) \\
\text { Female=11 }(100 \%)\end{array}$ \\
\hline Age & $43.79(11.20)$ & $42(11.64)$ \\
Money spent monthly on alcohol (Canadian dollars) & $28.09(37.74)$ & $13.42(18.37)$ \\
Money spent monthly on drugs (Canadian dollars) & $9.24(27.32)$ & $33.03(105.20)$ \\
Number of previous depressive episodes & $2.26(1.45)$ & $4(4.27)$ \\
Number of previous sick leaves due to depression & $1.67(.91)$ & $2.45(2.11)$ \\
Length of the last sick leave due to depression (months) & $9.17(7.25)$ & $4.98(3.56)$ \\
Importance given to work & $7.39(1.42)$ & $7.55(1.64)$ \\
\hline
\end{tabular}

All values represent mean (standard deviation) 
not ask for participants to refrain from receiving other services. Substance abuse or anxiety disorder were not exclusion criteria. Demographic information is presented in Table 1.

\section{Intervention}

The Healthy Minds group intervention was offered over a two-month timespan, once a week. Participants each had their own manual that contained information on all eight sessions (see Table 2), as well as homework to complete outside of the sessions. As can be seen in the Table 2, the material covers themes such as stress, problem solving, self-esteem and coping, but also helps in identifying and modifying cognitive biases in the workplace, which could be depressogenic (e.g., I am worthless) or anxiogenic (e.g., I am at risk of losing my job). Two co-counsellors led each session that included between five and seven participants per group. For the purpose of this study, the counsellors were trained by our team and hired for the study. Counsellor training took place over the course of two days by one of the investigators and co-developers of the manual (TL). The first group sessions were co-conducted and supervised by the developers of the manual (TL and MC) to ensure quality assurance purposes. The following group sessions were conducted by trained counsellors (co-counsellors in previous group sessions). The Healthy Minds intervention is greatly inspired by the validated CBT for supported employment (CBT-SE) intervention [35], developed for people with mental illness receiving supported employment services, with the same number of sessions (8) and similar themes. However, the Healthy Minds module specifically targets depression and issues related to RTW and proposes examples that are close to the participants' experiences. Typically, each session involves review of the homework (if applicable), presentation of the theme of the session, presentation of some didactic information, discussions and application of the material to oneself, writing relevant information to retain into one's manual, review of the session and presentation of the homework. The last session ends with review of the content and a small celebration. Booster sessions were offered to participants once a month for 6 months, if asked. This semi-structured group format has been demonstrated as successful in other studies from our team $[20,34,36]$, in terms of high participation rates and satisfaction levels as well as significant clinical improvements, and optimizes learning by offering an intensive intervention as well as tools, such as the manual, that facilitate information retention. The group intervention took place at the university, in a private meeting room. Participants attended on average $6.5 / 8(81 \%)$ of the sessions.

Table 2 Healthy minds intervention -8 session's content

\begin{tabular}{|c|c|c|}
\hline \# Session & Title & Content \\
\hline 1 & Coping with stress at work & $\begin{array}{l}\text { Recognizing stress, its effects on body, thoughts, and emotions } \\
\text { Recognizing stress in the various contexts at work } \\
\text { Sharing strategies to cope with stress at work }\end{array}$ \\
\hline $2-3$ & $\begin{array}{l}\text { Recognizing and modifying my dysfunctional beliefs linked to } \\
\text { work }\end{array}$ & $\begin{array}{l}\text { Learning the A-B-C's of CBT } \\
\text { Understanding the impact of negative or dysfunctional beliefs on } \\
\text { our emotions and behaviors } \\
\text { Getting facts and finding alternative beliefs }\end{array}$ \\
\hline 4 & $\begin{array}{l}\text { Overcoming obstacles linked to work functioning and maintain- } \\
\text { ing work }\end{array}$ & $\begin{array}{l}\text { Recognizing personal obstacles to maintaining a job and to work- } \\
\text { ing optimally } \\
\text { Sharing and practicing strategies to overcome these obstacles }\end{array}$ \\
\hline 5 & $\begin{array}{l}\text { To put in place needed work accommodations with the support of } \\
\text { the immediate supervisor }\end{array}$ & $\begin{array}{l}\text { Identify eventual work accommodations for facilitating the work } \\
\text { functioning } \\
\text { Discussing work accommodations with the supervisor } \\
\text { Prioritizing and implementing (ideally with the supervisor) the } \\
\text { work accommodations needed for maintaining employment }\end{array}$ \\
\hline 6 & My strengths and competencies related to work & $\begin{array}{l}\text { Understanding the power of negative self-attributions } \\
\text { Recognizing one's strengths and abilities with the help of others } \\
\text { in the group }\end{array}$ \\
\hline 7 & Accepting criticism and asserting myself appropriately & $\begin{array}{l}\text { Using techniques learned so far when confronted with criticism } \\
\text { (coping with stress, A-B-C, check facts, not jump to conclu- } \\
\text { sions, recognize strengths) } \\
\text { Learn relaxation, self-compassion and acceptance } \\
\text { Role-play polite self-assertion }\end{array}$ \\
\hline 8 & My best coping strategies for work & $\begin{array}{l}\text { Discussing disclosure of CMD and stigma at work } \\
\text { Reviewing coping strategies that work best for each person for } \\
\text { personal stressors, symptoms, moods and thoughts at work } \\
\text { Reviewing the manual, what was learned, liked, etc }\end{array}$ \\
\hline
\end{tabular}


Most participants attended all the sessions, with less than $30 \%$ of the participants missing sessions occasionally.

\section{Ethics and Informed Consent}

The study was approved by the Research Ethics Board from the Université du Québec à Montréal (Québec, Canada). Participants were compensated for their time spent on assessments but not for participating in the group intervention. Participants were allowed breaks during assessments and could even do the assessments over many meetings in order to avoid becoming too tired, as this often happens with people who were recently on sick leave linked to depression (residual symptoms).

\section{Measures}

Diagnosis of a depression: Trained interviewers, reaching the UCLA gold standard [37], delivered the SCID [34] semistructured interview at baseline, to ascertain a major depression diagnosis (according to the DSM-5 criteria). The number of lifetime depressive episodes was also documented.

\section{Depressive and Anxiety Symptoms}

We used the Beck depression and anxiety inventories. According to Burcusa and Iacono [38], the Beck Depression Inventory-II [39] is effective in determining a depressive episode. The BDI-II includes 21 items such as "Sadness: $0=\mathrm{I}$ do not feel sad, $1=\mathrm{I}$ feed sad, $2=\mathrm{I}$ am sad all the time and I can't snap out of it, $3=\mathrm{I}$ am so sad or unhappy that I can't stand it." Scores are derived by summing the responses to each of the 21 items, with scores of 0-13 considered as minimal range, 14-19 generally indicating mild depression, 20-28 suggesting moderate depression, and 29-63 indicating severe depression. The BDI-II was administered at each assessment time. As people with depression often have high comorbid anxiety symptoms [8, 17], we administered the Beck Anxiety Inventory (BAI) [40]. The BAI consists of 21 items self-rated on a scale from 0 to 3. Each item is descriptive of subjective, somatic, or panic-related symptoms of anxiety. As with the BDI, scores for the BAI are derived by summing the responses to each of the 21 items, with scores of $0-21$ considered as low anxiety, 22-35 indicating moderate anxiety, 36 and more suggesting severe levels of anxiety. The BDI-II and BAI were administered at each assessment time.

\section{Work Productivity}

To assess work productivity for people with CMDs, we used the French version [41] of the Endicott Productivity Scale (EWPS) [42], a self-report measure. The scale consists of 25 items on a 5 -point Likert scale (from $0=$ never to $4=$ almost always). The scale covers four productivity areas: attendance (absenteeism and time on task), quality of work, performance capacity, and personal factors, such as social (e.g., avoiding meetings), mental (e.g., concentration problems), physical (e.g., too tired), and emotional (e.g., feeling irritated or bored). For this study we used a reverse-total score from 0 (worst possible score) to 100 (best possible score), in which high scores represent a high level of accomplishment of working duties and tasks. This tool has been used in the Corbière et al.'s study [41] to test a theoretical model aimed at predicting work productivity over time of people with a psychiatric disability working in social firms.

\section{Analyses}

Data analyses were performed with R Statistics version 4.00 [43]. The mixed linear model was used to determine whether the outcome-depressive symptoms, anxiety symptoms, and work productivity - is predicted by time (baseline, postintervention and six-month follow-up) by group (experimental or control) interaction. Each of the three analyses included the following control variables: comorbid substance misuse (determined by money spent on alcohol and drugs), number of previous depressive episodes, number of sick leaves due to depression, length of the last sick leave due to depression, importance given to work (from $1=$ Work is not at all central to my life to $10=$ Work is the center of my life), age, and gender. For each analysis, the assumptions of multicollinearity of covariates, normality of residuals and homoscedasticity were verified and showed no anomalies. These analyses, if significant, were followed by a Tukey post-hoc analysis. The data was also examined by estimating the Bayes factors to ascertain the evidence of the interaction effects [44]. Given the pilot nature, Wilcoxon signed-rank test was used to determine the effect size within each group over time.

\section{Results}

\section{Depressive Symptoms (BDI Score)}

The mixed linear model was used to test the effect of time, group and timeX group interaction for the depressive symptoms score. We found a significant effect of time $(\mathrm{F}(2,43.6)=11.66 ; \mathrm{p}<0.001)$ (see Table 3$)$ and group $(F(1,25.1)=8.18 ; p<0.01)$, respectively in favor of the intervention group, with a drop of 12 points from $\mathrm{T} 0$ to $\mathrm{T} 2$ for the intervention group compared to a drop of 4 points from T0 to T2 for the control group, while the result for the interaction (time $\mathrm{x}$ group) was inconclusive $(F(2,44.4)=2.75 ; p=0.07)$. Indeed, the Bayes factor $(\mathrm{BF}=0.84)$ confirms the weak support of the data for 
Table 3 Results for clinical symptoms across time for each group (Intervention $\mathrm{N}=19$; Control $\mathrm{N}=11$ )

\begin{tabular}{|c|c|c|c|c|c|}
\hline & \multirow[t]{2}{*}{ Pre-intervention } & \multirow[t]{2}{*}{ Post-intervention } & \multirow[t]{2}{*}{ 6-month follow-up } & \multicolumn{2}{|c|}{ Wilcoxon Test } \\
\hline & & & & $\mathrm{Z}$ & $\mathrm{r}$ \\
\hline \multicolumn{6}{|c|}{ Depressive symptoms } \\
\hline Intervention & $21.6(10.8)$ & $15.8(8.9)$ & $9.5(4.03)$ & $2.45^{*}$ & 0.56 \\
\hline Control & $17(9.5)$ & $11.5(12)$ & $13(10.2)$ & 1.56 & 0.47 \\
\hline \multicolumn{6}{|c|}{ Anxiety symptoms } \\
\hline Intervention & $36.8(8.8)$ & $33.5(7.6)$ & $29.25(5.15)$ & $2.17 *$ & 0.50 \\
\hline Control & 33.7 (8.9) & $34.1(12.3)$ & $32.2(10.8)$ & 0.04 & 0.01 \\
\hline \multicolumn{6}{|c|}{ Work productivity } \\
\hline Intervention & $65.4(14.8)$ & $76.9(15.5)$ & $79.3(11.2)$ & $-1.96 *$ & 0.45 \\
\hline Control & $76.6(16.5)$ & $74.4(18.4)$ & $77.6(15.6)$ & 1.37 & 0.41 \\
\hline
\end{tabular}

All values represent mean (standard deviation)

$* * * p \leq 0.001, * * p \leq 0.01, * p \leq 0.05$ the interaction effect. When looking at the groups separately, with the Wilcoxon signed-rank test (Table 3), we find a big effect size for the intervention group $(r=0.56$, $\mathrm{p} \leq 0.05$ ). Furthermore, from a clinical point of view, at T0 (pre-intervention), the intervention group presented a moderate depression score (21.6) compared to a mild depression score for the control group (17), whereas the scores at the 6-month follow-up were clinically lower for the intervention group (9.5 vs. 13; Fig. 1A). Among control variables, only the age was significant, meaning older participants presented higher depressive symptom scores $(\mathrm{F}(1,29.6)=8.30 ; \mathrm{p}<0.01)$. The hypothesis $\mathrm{H} 1$ was consequently partially confirmed.
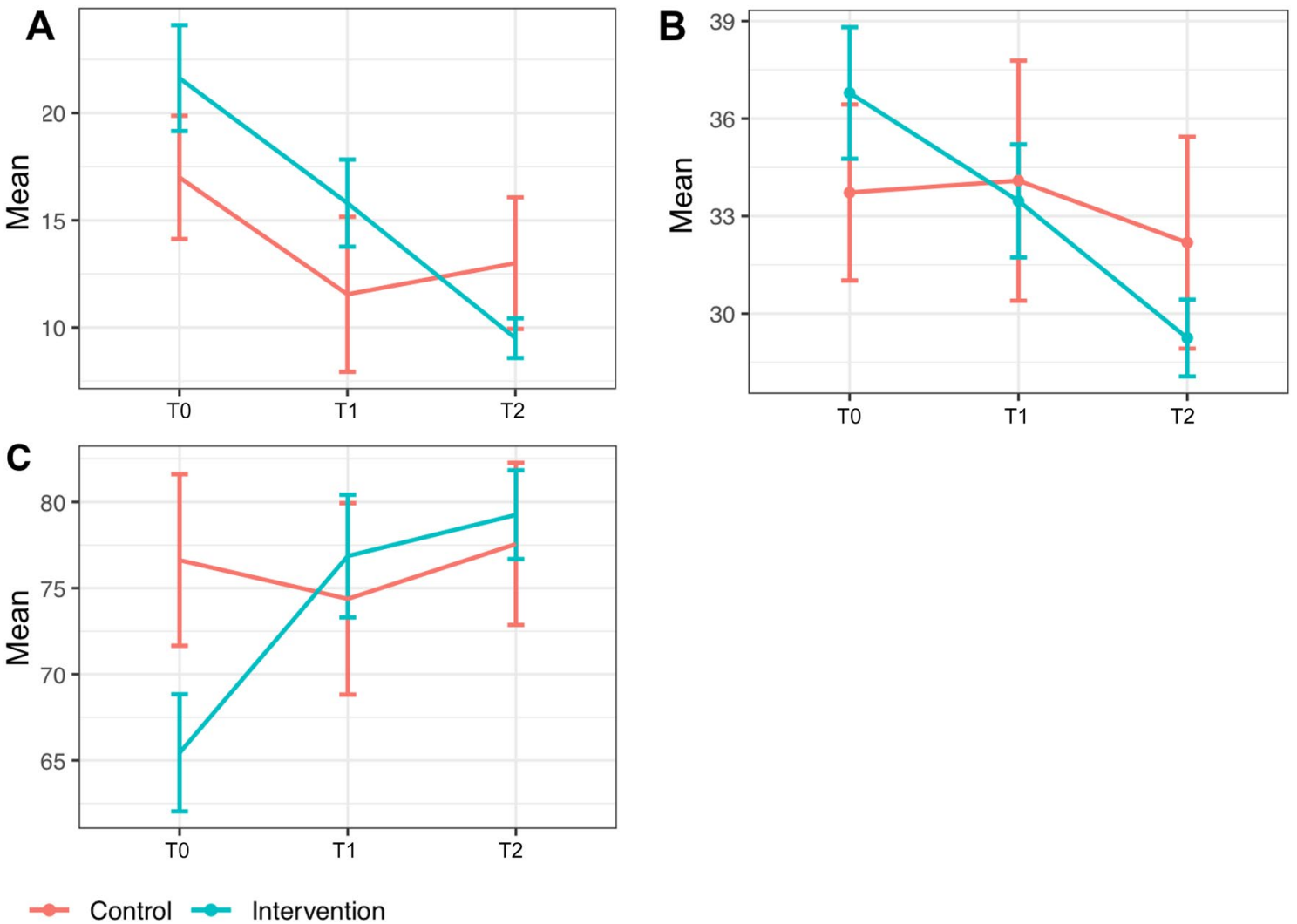

Fig. 1 Mean scores across time by group for depressive symptoms $(\mathbf{A})$, anxiety symptoms $(\mathbf{B})$ and work productivity $(\mathbf{C})$. T0 $=$ Baseline, T1 $=$ Post intervention, and T2 = Six-month follow-up 


\section{Anxiety Symptoms (BAI Score)}

The mixed linear model was used to test the effect of time, group and timeXgroup interaction for the anxiety symptoms score (Fig. 1). We found a significant effect of time ( $\mathrm{F}(2$, 45.9) $=5.36 ; \mathrm{p}<0.01$ ), a non-significant effect for group $(\mathrm{F}(1,28.6)=2.69 ; \mathrm{p}=0.11)$, with a drop of about 7.55 points from $\mathrm{T} 0$ to $\mathrm{T} 2$ for the intervention group compared to a drop of 1.5 points from $\mathrm{T} 0$ to $\mathrm{T} 2$ for the control group (see Table 3), while the result for the interaction timeXgroup was inconclusive $(F(2,46.4)=2.80 ; p=0.07)$. Indeed, the Bayes factor $(\mathrm{BF}=0.90)$ confirms the weak support of the data for the interaction effect. When looking at the groups separately, with the Wilcoxon signed-rank test (Table 3), we find a big effect size for the intervention group $(r=0.5$, $\mathrm{p} \leq 0.05$ ). Furthermore, considering a clinical point of view, at T0 (pre-intervention), the intervention group presented severe levels of anxiety (36.8) compared to a moderate score for the control group (33.7), but scores at 6-month followup were clinically lower for the intervention group (29.25 vs. 32.2). However, both groups presented moderate anxiety scores at 6-month follow-up (see Fig. 1B). The hypothesis $\mathrm{H} 2$ was consequently partially confirmed.

\section{Work Productivity (Endicott Work Productivity)}

The mixed linear model was used to test the effect of time, group and timeXgroup interaction for the work productivity score (Fig. 1). We found a significant effect of time ( $\mathrm{F}(2$, $43.8)=3.27 ; \mathrm{p}<0.05)$, a non-significant effect for group $(\mathrm{F}(1,29.8)=0.72 ; \mathrm{p}=0.40)$, as well as of the interaction between time and group $(\mathrm{F}(2,45.6)=4.39 ; \mathrm{p}<0.02)$. Indeed, the Bayes factor $(\mathrm{BF}=4.47)$ confirms the acceptable support of the data for the interaction effect. A post-hoc test, using Tukey's correction, showed that the difference was between times T0-T1 $(\mathrm{p}<0.05)$ and T0-T2 $(\mathrm{p}<0.01)$ for the intervention group. When looking at the groups separately, with the Wilcoxon signed-rank test (Table 3), we find a medium effect size for the intervention group $(r=0.45, p \leq 0.05)$. The hypothesis $\mathrm{H} 3$ was consequently confirmed.

\section{Discussion}

Although more studies are warranted, our results suggest that the Healthy Minds group intervention could be useful in helping people after sick leave due to depression ensure sustainable RTW. Indeed, our results are promising, with large withingroup effect sizes for the intervention group, in terms of fewer depressive and anxiety symptoms. Although the timeXgroup interactions were not significant for depressive and anxiety symptoms, the results show a trend $(p=0.07)$, leading us to suggest that a larger sample might lead to a statistically significant result. It is also important to consider the width of the confidence interval; such large confidence intervals make statistical significance more difficult to attain in small samples. Furthermore, we obtained increased work productivity (medium effect size), up to six months post-intervention in those having received the group intervention when compared to those in a return-to-work process who did not attend the groups. There are a few elements to consider, other than sample size, when looking at these results. The intervention group presented with more severe symptoms on both scales, and also performed more poorly in terms of work productivity, compared to the control condition, at baseline. One might wonder if the clinically significant improvements seen were simply linked to having more room for improvement, which might have happened with or without the intervention. Two arguments suggest otherwise. For one, participants in the intervention group attended the group intervention diligently (over $80 \%$ participation). Second, all the participants recruited were either just about to return to work or had recently returned, suggesting that their symptoms had been judged as stabilized by their following physician. In fact, these results might suggest that the Healthy Minds intervention could help even those with more severe symptoms.

Our results support those of Joyce et al.'s meta-analysis that favored work focused CBT over standard CBT or usual interventions for people with CMDs [13], suggesting stronger effects on symptoms and work-related outcomes when the intervention is more closely linked to the work context. According to Gjengedal et al. [45], clinical changes on the BAI or BDI-II need to be greater that 9 to be considered clinically significant. In our study, for depressive symptoms particularly, the score changed from 21.6 to 9.5. (> 10 points) for the Healthy Minds group whereas the control group, reduced its score from 17 to 13, from pre-intervention to 6-month follow-up. For anxiety symptoms the decrease of 9 points was not observed, although a constant and statistically significant drop across time for the intervention group compared to the control group was clear (Table 3). Given the Healthy Minds intervention specifically focuses on depression, this is not surprising.

Our results are close to those reported by Ito et al.'s [17] pilot study, whereby work-focused cognitive behavioral group therapy ( 8 sessions) for Japanese workers on sick leave due to depression resulted in improvements in anxiety and depressive symptoms, as well as in social functioning from pre to post intervention. Our results are also close to those of Winter et al. [46], who conducted a pilot study with 20 German workers with a major depression who received cognitivebehavioral therapy, with an integrated, standardized RTW module (W-CBT). They also found that work ability significantly improved and depressive symptoms were significantly reduced in their pre-post comparison. Contrary to the current study, these two studies were limited methodologically by the fact that no control condition was included. 
In the analyses, we have taken into account several control variables, such as comorbid substance misuse, number of previous depressive episodes, number of sick leaves, length of the last sick leave, subjective importance given to work, age, and gender. Among these, only age was significantly related to higher depressive symptoms. In other terms, older participants presented with higher scores of depressive symptoms and, in turn those with more severe depressive symptoms rated lower levels of work productivity. These results corroborate with Lammerts' study [47] showing that younger age was associated with better odds of sustainable RTW when considering sick-listed workers with a depressive or anxiety disorder over the course of two years. However, in Endo et al.'s study [22], age was not significant in predicting recurrent sickness absence. It seems important to intervene more specifically with older workers who are potentially at higher risk of experiencing recurrent sickness absences.

In order to better understand the impact of interventions like Healthy Minds, future intervention studies could also assess other variables, such as RTW self-efficacy or perceived barriers to employment. As Brenninkmeijer et al.'s study [33] showed, Individuals with high baseline selfefficacy were better able to benefit, in terms of full RTW, from CBT interventions focusing on work. Regardless of the intervention used, Corbière et al. [48] showed that perceived barriers related to cognitive deficits and fear of relapses significantly and negatively predicted RTW for people with CMDs. They further documented that the most common work accommodations put in place during the RTW for people with depression or a CMD were work schedule, task modifications, job change, work environment change, supervisor support and feed-back [49, 50]. Bolo et al. [26] found that employees who received workplace adjustments (e.g., schedule flexibility, adequate supervisor support) avoided symptomatic relapses one year later (compared to those who did not receive such accommodations). In our study, although we discussed work accommodations and recommended following this through with the supervisor, we did not specifically assess this variable nor its impact on the outcomes in our study. As such, we cannot determine the impact of the presence or not of accommodations on our results (i.e. improvement in symptoms and work productivity).

More and more, experts recommend developing interventions that integrate workplace and clinical aspects for people on sick-leave due to depression [8, 10, 14]. These interventions need to consider the work context as well as the clinical manifestations of the worker [45]. Given that depressive and anxiety symptoms can negatively impact one's RTW, it is important to consider both clinical and work outcomes when evaluating RTW and work sustainability. Recent developments for preventing sustained or recurrent depressive symptoms after RTW can be found in the literature, mostly favoring interventions using cognitive behavioral concepts and strategies, either in group or individual formats [16, 17, 46]. According to Arends et al.'s [24] trajectory analyses following RTW after a CMD-related sick leave, workers continue to experience work functioning and clinical challenges over time, even at one-year follow-up. It is therefore essential to continue evaluating clinical and work outcomes in the long run, particularly for people with depressive disorders, in order to also better understand the interaction between changes in work functioning/productivity and in symptoms. Future studies could investigate simultaneous progression of symptoms and work outcomes in longitudinal designs from the beginning of gradual RTW to post RTW ( $>2$ years and more) in order to better understand sustainable RTW in terms of clinical (depressive and anxiety symptoms) and work outcomes such as work productivity.

The main limitations of our study are its sample size, and the randomization strategy. Recruitment into trials for mental health interventions with a treatment-as-usual condition is notoriously difficult [30]. As mentioned by Cramer et al. [30], participants are open to take part in a mental health intervention, especially when it is brief, appears helpful, and considered not too demanding. To take part in a study, including interviews and assessments, can be difficult for many who present with depression-related challenges such as fatigue, and lack of motivation. The groups were offered in the evening, after working hours, which might have deterred those with lower energy levels. In this study, we struggled to recruit and keep people in the control condition (even if they received a small stipend and could conduct the interviews online or over the phone). For the intervention group, the participation rate was high but initial refusal rates were also high, with the reasons mentioned being linked to fatigue and stress linked to the recent RTW. Another limitation is linked to the fact that we did not document all the services received by the participants in this study. It is however likely that these would even out across the two conditions, but we do not have this information. Recent technological advances, namely linked to the COVID-19 pandemic, bring us to consider offering the Healthy Minds group via online webconferencing. Luo et al.'s systematic review [51] suggests that online CBT is effective for reducing depression symptom severity. Furthermore, Hesketh et al. [52] specified that attrition rates tended to be lower for online interventions where guidance was provided. We have recently conducted online CBT groups for another clientele and found results comparable to in-person groups [35], even in terms of group cohesion (e.g., feelings of relating to others in the group). In terms of sample size, a post-hoc power analysis suggested that 33 participants per condition (total $\mathrm{N}=66$ ) would be needed to achieve a power of $80 \%$ for an eventual study with this intervention. Given our promising results, we are planning a future pragmatic trial that would enable us to test the efficacy of the Healthy Minds 
group intervention offered remotely, via webconferencing, for people with CMDs (including depression and anxiety disorders). Such a real-world trial would allow to compare the intervention to a wait-list control group, while training group leaders (such as occupational therapists/counsellors) from rehabilitation clinics or work settings, and thus, maximize applicability and generalizability.

In conclusion, this pilot study provides an initial indication that the Healthy Minds intervention is promising in terms of clinical and work productivity outcomes. The use of a manual and a brief training for the facilitators, with limited supervision, appeared to be successful to ensure the quality delivery of the intervention. Previously, participants' subjective appreciation of the group experience revealed that the intervention was perceived as very useful, particularly CBT strategies adapted to the work context [20]. Considering the increasing number of people on sick leave due to CMDs, and depression in particular, as well as the high risk of sustained or recurrent symptoms, this pilot study provides important support for a larger future pragmatic trial. Healthy Minds could be offered via online webconferencing, allowing access to people living in remote areas or to those struggling to access a group after their workday.

Acknowledgements We would like to thank the participants and referring sites. We would also like to extend our thanks to the reviewer 1, whose generous comments greatly helped improve the article.

Funding The research was supported by a Grant from Healthy Minds Canada.

Data Availability Data are available to researchers upon request.

Code Availability (Software Application or Custom Code) The R code was developed by the team and is available upon request.

\section{Declarations}

Conflict of interest On behalf of all authors, the corresponding author states that there is no conflict of interest.

\section{References}

1. Ervasti J, Joensuu M, Pentti J, Oksanen T, Ahola K, Vahtera J, Kivimäki M, Virtanen M. Prognostic factors for return to work after depression-related work disability: a systematic review and meta-analysis. J Psychiatr Res. 2017;95(1):28-36.

2. Patten SB. A major depression prognosis calculator based on episode duration. Clin Pract Epidemiol Ment Health. 2006;2(1):13.

3. Patten SB, Williams JVA, Lavorato DH, Fiest KM, Bulloch AGM, Wang J. The prevalence of major depression is not changing. Can J Psychiatry. 2015;60(1):31-4.

4. Patten SB, Juby H. Profil de la dépression clinique au Canada. [A profile of clinical depression in Canada]. PRISM, University of Calgary. 2008. https://doi.org/10.11575/PRISM/10748
5. World Health Organization. Depression and Other Common Mental Disorders: Global Health Estimates. WHO/MSD/ MER/2017.2. Geneva, Switzerland. 2017.

6. World Health Organization (WHO). Mental health policies and programs in the workplace. Mental Health Policy and Service Guidance Package. Geneva, Switzerland. 2005.

7. Bellón JÁ, Conejo-Cerón S, Cortés-Abela C, Pena-Andreu JM, García-Rodríguez A, Moreno-Peral P. Effectiveness of psychological and educational interventions for the prevention of depression in the workplace: a systematic review and metaanalysis. Scand J Work Environ Health. 2019;45(4):324-32.

8. Nigatu YT, Liu Y, Uppal M, McKinney S, Rao S, Gillis K, Wang J. Interventions for enhancing return to work in individuals with a common mental illness: systematic review and meta-analysis of randomized controlled trials. Psychol Med. 2016;46(16):3263-74.

9. Dewa CS, Loong D, Bonato S, Hees H. Incidence rates of sickness absence related to mental disorders: a systematic literature review. BMC Public Health. 2014;14(1):205.

10. Gili M, Vicens C, Roca M, Andersen P, McMillan D. Interventions for preventing relapse or recurrence of depression in primary health care settings: a systematic review. Prev Med. 2015;76(Suppl):S16-21.

11. Clarke K, Mayo-Wilson E, Kenny J, Pilling S. Can non-pharmacological interventions prevent relapse in adults who have recovered from depression? A systematic review and meta-analysis of randomised controlled trials. Clin Psychol Rev. 2015;39:58-70.

12. de Zwart PL, Jeronimus BF, de Jonge P. Empirical evidence for definitions of episode, remission, recovery, relapse and recurrence in depression: a systematic review. Epidemiol Psychiatr Sci. 2019;28(5):544-62.

13. Joyce S, Modini M, Christensen H, Mykletun A, Bryant R, Mitchell PB, Harvey SB. Workplace interventions for common mental disorders: a systematic meta-review. Psychol Med. 2016;46(4):683-97.

14. Martin MHT, Nielsen MBD, Pedersen J, Rugulies R. Stability of return to work after a coordinated and tailored intervention for sickness absence compensation beneficiaries with mental health problems: results of a two-year follow-up study. Disabil Rehabil. 2015;37(22):2107-13.

15. Cullen KL, Irvin E, Collie A, et al. Effectiveness of workplace interventions in return-to-work for musculoskeletal, pain-related and mental health conditions: an update of the evidence and messages for practitioners. J Occup Rehabil. 2017;28(1):1-15.

16. Arends I, Bultmann U, Nielsen K, van Rhenen W, de Boer MR, van der Klink JJ. Process evaluation of a problem solving intervention to prevent recurrent sickness absence in workers with common mental disorders. Soc Sci Med. 2014;100:123-32.

17. Ito $\mathrm{D}$, Watanabe $\mathrm{A}$, Takeichi $\mathrm{S}$, Ishihara $\mathrm{A}$, Yamamoto $\mathrm{K}$. A Preliminary study of work-focused cognitive behavioural group therapy for Japanese workers. Behav Cogn Psychother. 2019;47(2):251-6.

18. Wisenthal A, Krupa T, Kirsh BH, Lysaght R. Cognitive work hardening for return to work following depression: an intervention study: Le réentraînement cognitif au travail pour favoriser le retour au travail à la suite d'une dépression : étude d'intervention. Can J Occup Ther Rev Can Ergother. 2018;85(1):21-32.

19. World Health Organization (WHO). Depression. https://www. who.int/news-room/fact-sheets/detail/depression. 2020. Accessed Mar 2021.

20. Lecomte T, Corbière M. A group cognitive-behavioural intervention to prevent depression relapse in individuals having recently returned to work: protocol and feasibility. Sante Ment Que. 2017;42(2):87-103.

21. Robert A, Combalbert N, Pennequin V. Étude des profils de distorsion cognitive en fonction des états anxieux et dépressifs chez des 
adultes tout-venant. [Study of cognitive distortion profiles on anxiety and depressive states in ordinary people]. Ann Méd-Psychol Rev Psychiatr. 2018;176(3):225-30.

22. Endo M, Muto T, Haruyama Y, Yuhara M, Sairenchi T, Kato R. Risk factors of recurrent sickness absence due to depression: a two-year cohort study among Japanese employees. Int Arch Occup Environ Health. 2015;88(1):75-83.

23. Dewa CS, Loong D, Bonato S. Work outcomes of sickness absence related to mental disorders: a systematic literature review. BMJ Open. 2014;4(7):e005533.

24. Arends I, Almansa J, Stansfeld SA, Amick BC, van der Klink JJL, Bültmann U. One-year trajectories of mental health and work outcomes post return to work in patients with common mental disorders. J Affect Disord. 2019;257:263-70.

25. Nieuwenhuijsen K, Faber B, Verbeek JH, Neumeyer-Gromen A, Hees HL, Verhoeven AC, van der Feltz-Cornelis CM, Bültmann $\mathrm{U}$. Interventions to improve return to work in depressed people. Cochrane Database Syst Rev. 2014;12(2):CD006237.

26. Bolo C, Sareen J, Patten S, Schmitz N, Currie S, Wang J. Receiving workplace mental health accommodations and the outcome of mental disorders in employees with a depressive and/or anxiety disorder. J Occup Environ Med. 2013;55(11):1293-9.

27. Finnes A, Enebrink P, Ghaderi A, Dahl J, Nager A, Ost L-G. Psychological treatments for return to work in individuals on sickness absence due to common mental disorders or musculoskeletal disorders: a systematic review and meta-analysis of randomized controlled trials. Int Arch Occup Environ Health. 2019;92(3):273-93.

28. Adler DA, McLaughlin TJ, Rogers WH, Chang H, Lapitsky L, Lerner D. Job performance deficits due to depression. Am J Psychiatry. 2006;163(9):1569-76.

29. Lerner D, Henke RM. What does research tell us about depression, job performance, and work productivity? J Occup Environ Med. 2008;50(4):401-10.

30. Cramer H, Salisbury C, Conrad J, Eldred J, Araya R. Group cognitive behavioural therapy for women with depression: pilot and feasibility study for a randomised controlled trial using mixed methods. BMC Psychiatry. 2011;11(1):82.

31. Hvenegaard M, Moeller SB, Poulsen S, Gondan M, Grafton B, Austin SF, Kistrup M, Rosenberg NGK, Howard H, Watkins ER. Group rumination-focused cognitive-behavioural therapy (CBT) $v$. group CBT for depression: phase II trial. Psychol Med. 2020;50(1):11-9.

32. Weiner L, Garcia-Krafes E, Garcia S, Berthomier C, Morali A, Metzger J-Y, Weibel S, Javelot H, Bertschy G. IDEM-dépression: caractéristiques et évaluation d'un groupe ouvert combinant psychoéducation et thérapie cognitivo-comportementale. [IDEM-depression: characteristics and evaluation of an open group that combines psychoeducation andcognitive-behavior therapy]. L'Encéphale. 2018;44(2):141-7.

33. Brenninkmeijer V, Lagerveld SE, Blonk RWB, Schaufeli WB, Wijngaards-de Meij LDNV. Predicting the effectiveness of workfocused CBT for common mental disorders: the influence of baseline self-efficacy, depression and anxiety. J Occup Rehabil. 2019;29(1):31-41.

34. First M, Spitzer R, Gibbon M, William J. Clinical interview for DSM- IV Axis I disorders, clinician version (SCID-CV). 1996.

35. Lecomte $\mathrm{T}$, Corbière $\mathrm{M}$, Giguère $\mathrm{C}$-E, Titone $\mathrm{D}$, Lysaker $\mathrm{P}$. Group cognitive behaviour therapy for supported employmentresults of a randomized controlled cohort trial. Schizophr Res. 2020;215:126-33.

36. Lecomte T, Leclerc C, Corbière M, Wykes T, Wallace CJ, Spidel A. Group cognitive behavior therapy or social skills training for individuals with a recent onset of psychosis? Results of a randomized controlled trial. J Nerv Ment Dis. 2008;196(12):866-75.

37. Ventura J, Green MF, Shaner A, Liberman RP. Training and quality assurance with the Brief Psychiatric Rating Scale: "The drift busters." Int J Methods Psychiatr Res. 1993;3(4):221-44.

38. Burcusa SL, Iacono WG. Risk for recurrence in depression. Clin Psychol Rev. 2007;27(8):959-85.

39. Beck AT, Steer RA, Brown GK. BDI-II, Beck Depression Inventory: manual. San Antonio: Psychological Corporation; 1996.

40. Beck AT, Steer RA. BAI, Beck Anxiety Inventory: manual. San Antonio: Psychological Corporation; 1993.

41. Corbière M, Zaniboni S, Dewa CS, Villotti P, Lecomte T, Sultan-Tareb H, Hupe J, Fraccaroli F. Work productivity of people with a psychiatric disability working in social firms. Work. 2019;62(1):151-60.

42. Endicott J, Nee J. Endicott Work Productivity Scale (EWPS): a new measure to assess treatment effects. Psychopharmacol Bull. 1997;33(1):13-6.

43. R Core Team. R: a language and environment for statistical computing. R Foundation for Statistical Computing. 2020. https://www.Rproject.org/.

44. Jarosz A, Wiley J. What are the odds? A practical guide to computing and reporting bayes factors. J Probl Solving. 2014. https://doi. org/10.7771/1932-6246.1167.

45. Gjengedal RGH, Reme SE, Osnes K, Lagerfeld SE, Blonk RWB, Sandin K, Berge T, Hjemdal O. Work-focused therapy for common mental disorders: a naturalistic study comparing an intervention group with a waitlist control group. Work. 2020;66(3):657-67.

46. Winter L, Geldmacher J, Plücker-Boss K, Kahl KG. Integration of a return-to-work module in cognitive behavioral therapy in patients with major depressive disorder and long-term sick leave - a feasibility study. Front Psychiatry. 2020. https://doi.org/10.3389/fpsyt.2020. 00512.

47. Lammerts L, Schaafsma FG, Eikelenboom M, Vermeulen SJ, van Mechelen W, Anema JR, Penninx BW. Longitudinal associations between biopsychosocial factors and sustainable return to work of sick-listed workers with a depressive or anxiety disorder. J Occup Rehabil. 2016;26(1):70-9.

48. Corbière M, Negrini A, Durand M-J, St-Arnaud L, Briand C, Fassier J-P, Loisel P, Lachance J-P. Development of the Return-to-Work Obstacles and Self-Efficacy Scale (ROSES) and validation with workers suffering from a common mental disorder or musculoskeletal disorder. J Occup Rehabil. 2017;27(3):329-41.

49. Bastien M-F, Corbière M. Return-to-work following depression: what work accommodations do employers and human resources directors put in place? J Occup Rehabil. 2019;29(2):423-32.

50. Sikora A, Schneider G, Stegmann R, Wegewitz U. Returning to work after sickness absence due to common mental disorders: study design and baseline findings from an 18 months mixed methods follow-up study in Germany. BMC Public Health. 2019;19(1):1653.

51. Luo C, Sanger N, Singhal N, et al. A comparison of electronicallydelivered and face to face cognitive behavioural therapies in depressive disorders: a systematic review and meta-analysis. EClinicalMedicine. 2020. https://doi.org/10.1016/j.eclinm.2020.100442.

52. Hesketh R, Strang L, Pollitt A, Wilkinson B. What do we know about the effectiveness of workplace mental health interventions? Literature review. The Policy at Institute King's college London; 2020

Publisher's Note Springer Nature remains neutral with regard to jurisdictional claims in published maps and institutional affiliations. 